\title{
Cardiovascular effects of cocaine
}

\author{
Corresponding author: \\ Michat Siedlaczek, Department of \\ Health Promotion, \\ Nicolaus Copernicus University, \\ Collegium Medicum, Torun, Poland, \\ e-mail: \\ michalsiedlaczekmed@gmail.com \\ Medical Research Journal 2019; \\ Volume 4, Number 2, 110-115 \\ 10.5603/MRJ.a2019.0012 \\ Copyright (c) 2019 Via Medica \\ ISSN 2451-2591
}

\begin{abstract}
A case of a 39-year-old man, who was taking cocaine 2-3 times a week for several years. The article contains the possible impact of cocaine use on the cardiovascular system and differential diagnosis in this patient. Key words: cocaine, cardiovascular
\end{abstract}

Med Res J 2019; 4 (2): 110-115

\section{Introduction}

Cocaine is one of the most commonly used illegal drug worldwide. It is highly psychologically addictive, but it has no physical withdrawal effects. The main mechanism action of cocaine is the inhibition of noradrenaline and dopamine re-uptake from the synaptic cleft which causes overstimulation of alpha and beta-adrenergic receptors. [1] Cocaine abuse may cause acute and chronic cardiovascular diseases - myocardial ischemia, myocardial infraction, arrhythmias, cardiomyopathy, myocarditis, hypertension, aortic dissection. (Fig. 1.) Cocaine users have 4-8 times higher mortality compared to the general population. It is also the most common cause of drug-related deaths.

\section{Case report}

A 39-year-old male with pneumonia and heart failure (de novo), with no previous of cardiac problems, presented shortness of breath. He admitted that he was taking cocaine 2-3 times a week for several years by inhaling it cocaine through his nose. Three weeks ago he underwent a laryngological surgery due to chronic sinusitis.

During the physical examination, the patient had a blood pressure of $105 / 70 \mathrm{mmHg}$ and his heart rate was 110 beats/min and regular. In cardiac auscultation, a high-pitched holo-systolic murmur on the apex, radiating to the armpit could be heard. Electrocardiogram revealed sinus rhythm with left ventricular overload and hypertrophy, negative T in leads I, II, aVL, V4-V6 (Fig. 2).

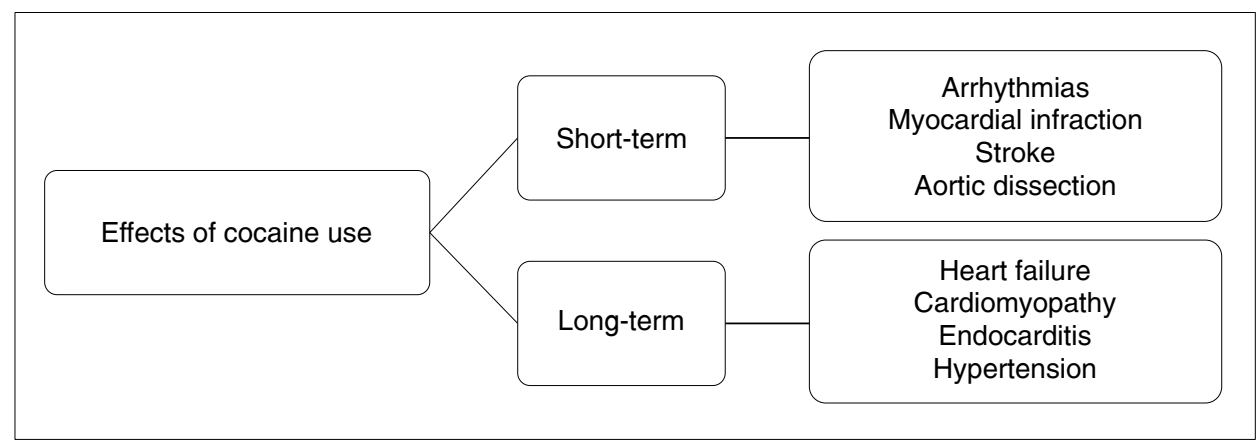

Figure 1. Short-Term and long-term effects of cocaine use 


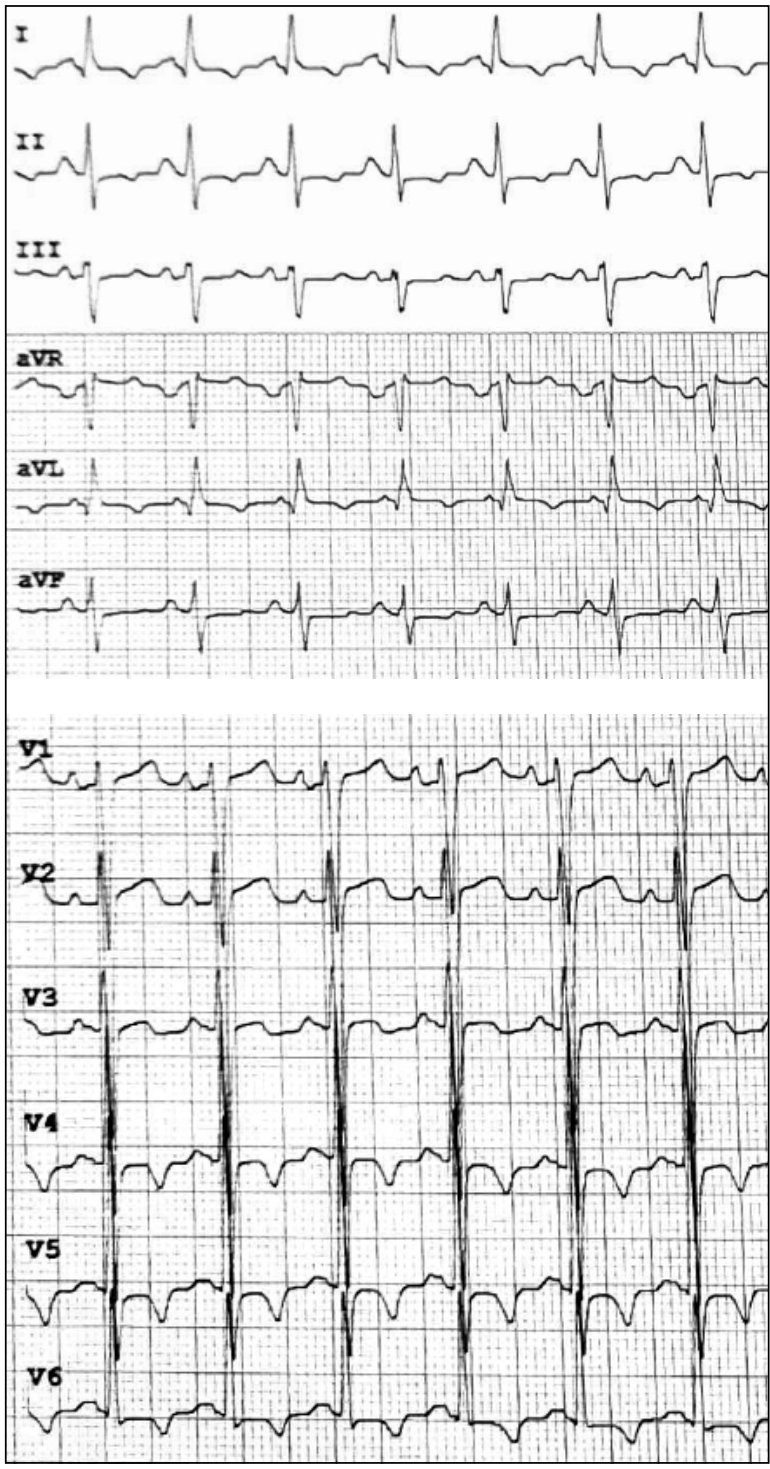

Figure 2. ECG of presented patient

Troponin I levels peaked at $77 \mathrm{ng} / \mathrm{ml}$, creatine was $0,97 \mathrm{mg} / \mathrm{dl}$, Btype natriuretic peptide was $2003 \mathrm{pg} / \mathrm{ml}$. A chest X-ray revealed an enlarged cardiac silhouette (Fig. 3). An echocardiogram demonstrated akinesis of the apex, anterior wall and interventricular septum, hypokinesis of other left ventricular walls, enlargement of all heart cavities, left ventricular ejection fraction of $25 \%$. Coronarography didn't show any abnormalities in coronary vessels (Fig. 4). Cardiac MRI showed dilation and severe retardation of the systolic function of both chambers with no underlying cause. There wasn't contrast enhancement typical to inflammation or myocardial ischemia.

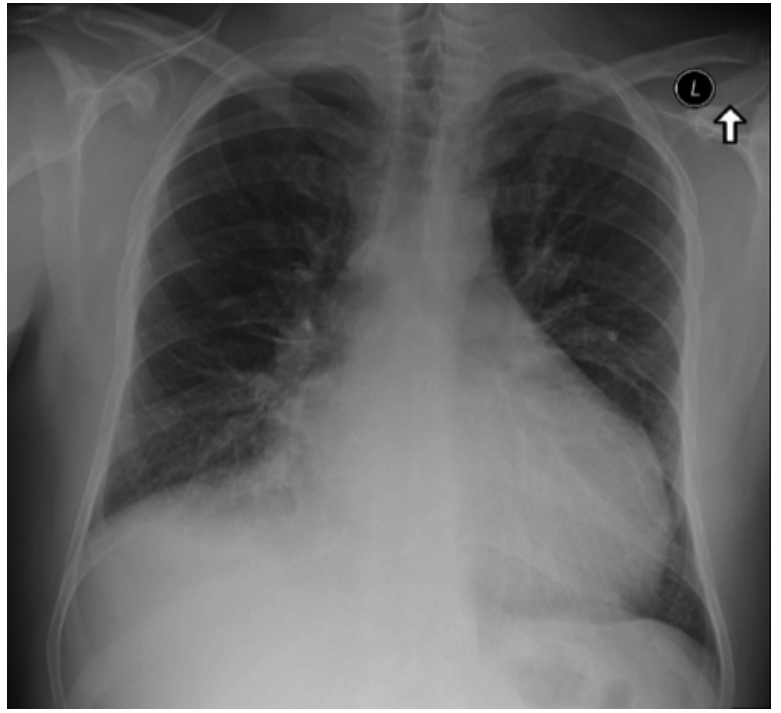

Figure 3. Chest X-Ray of a presented patient

\section{Cocaine-inducted acute myocardial infraction}

Overstimulation of beta-adrenergic receptors, caused by cocaine, increases contractility and heart rate, which leads to a higher oxygen request [2]. Moreover, cocaine is causing overstimulation alfa- 1 and alfa2 receptors, which causes coronary artery spasm. The ischemic effect appears when heart rate and blood pressure is higher, requiring more oxygen supply (Fig. 5). Cocaine also activates platelet aggregation, which is leading to the formation of blood clots in the coronary vessels. It also accelerates atherosclerosis [3].

However, coronarography may not show any abnormalities in coronary vessels [4]. In patients with cocaine-related pain, a heart attack occurs in $6 \%$ of cases. Cocaine inducted acute myocardial infraction is the most common among the population of patients between the ages of 18-45 [5-6]. It needs to be suspected in young patients with chest pain.

The risk of a heart attack increases 24 times directly after using cocaine. Most infractions happen during the first 3 hours after cocaine use [7]. Complications rarely occur after 12 hours, so patients should be monitored by ECGs and cardiac troponins for at least 12 hours [8]. Cocaine is affiliated with an increased risk of acute coronary syndrome even without the presence of coronary heart disease, due to coronary artery spasms.

The treatment is similar to the one that is used in an acute myocardial infraction. Until recently it was considered that it is not recommended to use B-blockers in treatment, because of vasoconstriction properties. How- 

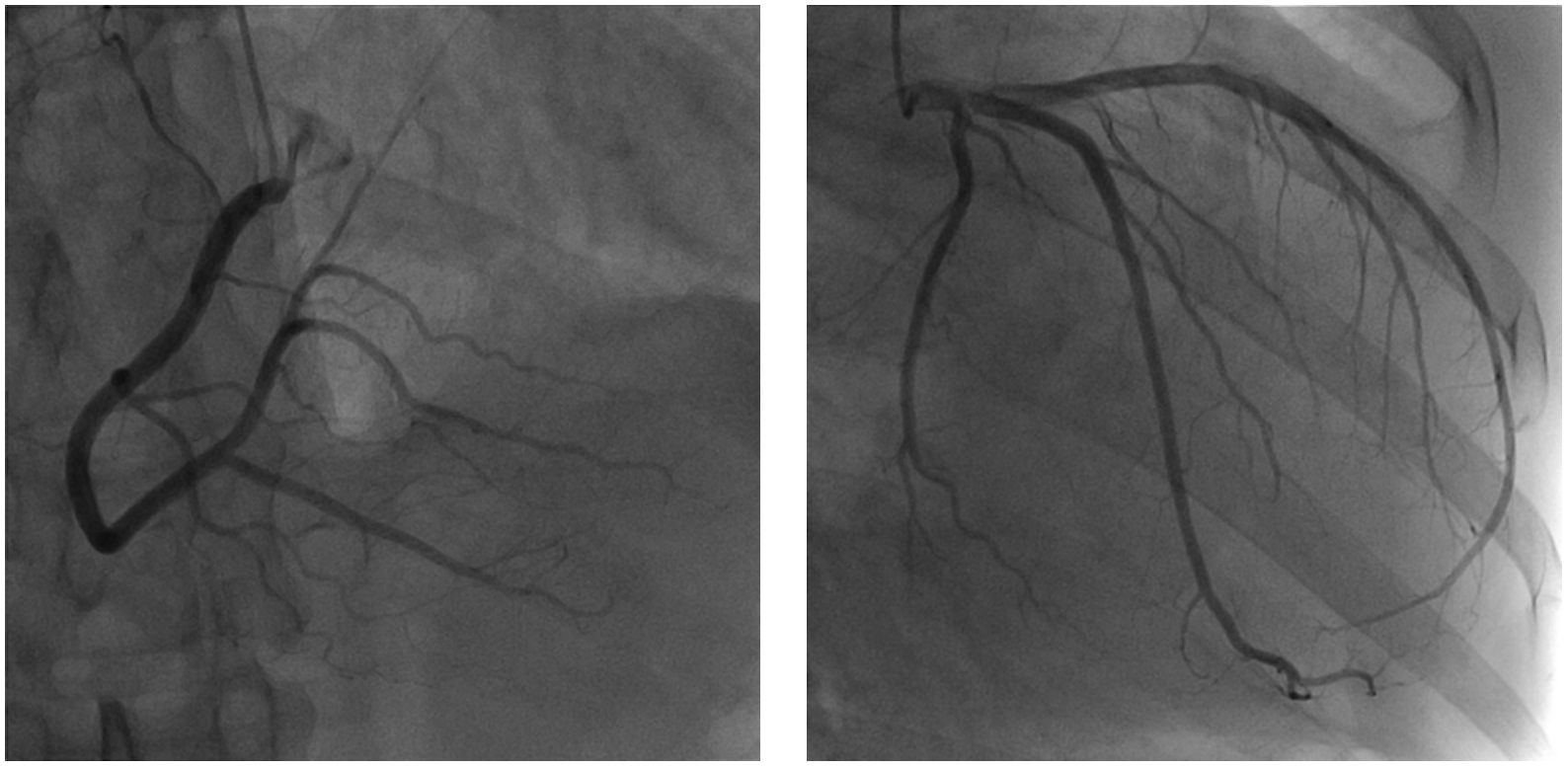

Figure 4. Coronarography of the presented patient

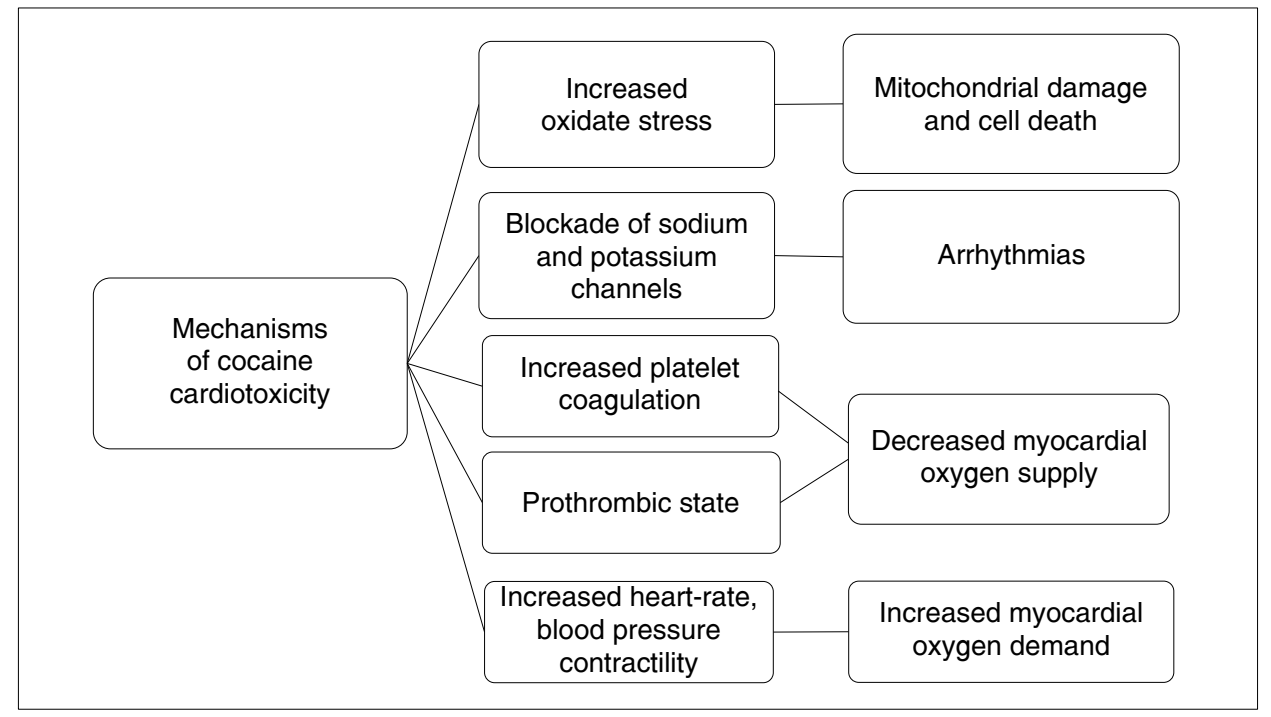

Figure 5. Mechanisms of cocaine inducted cardiotoxicity

ever because of the fact, that a lot of patients didn't admit that they used cocaine, received B-blockers and they didn't affect them negatively, but even they had a beneficial effect. [9] B-blockers are causing a lower request for oxygen. Treatment was associated with lower rates of deaths. The guidelines of ACC/AHA from 2012 states that it is acceptable to use Bblockers at the patients with hypertension or tachycardia if they received vasodilator drug [7]. Additionally, it is recommended to use benzodiazepines for the patients who are hyper excitable with hypertension and tachycardia [10]. Benzodiazepines reduce the hemodynamic effects of cocaine. Sedation is also indicated in patients with psychomotor agitation.
The lack of coronary artery stenosis in coronarography, especially in young patients with the acute coronary syndrome, should lead to suspicion of taking cocaine as a cause. The guidelines of ACC/AHA from 2008-2012 recommended to using bare-metal stents in cocaine abusers. [7]

The psychological state and euphoria associated with cocaine use, reduce the number of patients, who were referred to a hospital. That is why the reports on the number of heart attacks caused by cocaine use are underestimated.

With regard to the case report, the possibility of myocardial infarction was ruled out because of the lack 
of chest pain and slightly increased Tnl without typical dynamic, characteristic for the myocardial infraction.

Coronarography didn't show any abnormalities in coronary vessels.

\section{Aortic dissection}

Cocaine induces the apoptosis of smooth muscle cells, which build the vessel wall, making them more susceptible to damage [11]. Sudden increase of blood pressure up to high values, after exposure to cocaine, may cause aortic dissection. It is estimated that $0.5 \%$ is connected with cocaine usage. Should be expected aortic dissection especially in young patients with chest pain. First line treatment is controlling blood pressure, heart rate and level of pain. Further therapy is surgery. Patients have a high risk of dangerous complications and even death.

In this particular case report, aortic dissection is not expected because there was no chest pain. Also, there was no evidence of aortic dissection in imaging studies.

\section{Cardiomyopathy}

Cardiomyopathy in cocaine users is caused by a direct toxic effect on myocytes, oxidative stress, calcium channel dysfunction and also excessive adrenergic stimulation. Toxic influence of cocaine is causing inflammation of the heart muscle, fibrosis and as a result heart failure. Oxidative stress has a toxic effect on the myocardium. It is caused by high level of peroxides and free radicals, which are damaging all components of cardiomyocytes. [12] Raised calcium inflow into smooth muscle cells results in increased contraction force, but when it is chronic, it weakens the myocardium, causes overgrowth and decreases the left ventricle ejection fraction. [13] Excessive adrenergic stimulation caused by the inhibition of noradrenaline and dopamine reuptake causes an increase in heart rate and elevated blood pressure. [14] This affects the remodelling of the myocardium. Improvement of the left ventricle ejection fraction is possible after reaching total abstinence from cocaine.

Cocaine-associated cardiomyopathy should be suspected in young patients with heart failure. Symptoms reported by patients are similar to those with dilated cardiomyopathy. Mostly it is dyspnea and fatigue. [15] However it was revealed that symptoms such as leg oedema are much less intense. Cardiomyopathy usually has a more severe course. Usually, patients also present symptoms of increased adrenergic stimulation, such as tachycardia, hyper-tension and those associated with the psychotropic action of cocaine. In a physical examination, it's possible to notice symptoms of cocaine usage - depending on the route of administration of the drug such as scars after intravenous injections or damage of the nasal septum.

It is reasonable to use B-blocker treatment in patients with cocaine-related cardiomyopathy who had abstinence for more than 6 months, as standard therapy of the left ventricular dysfunction.

The clinical picture of this patient led to the diagnosis - cardiomyopathy. The patient presented dyspnea and impaired of effort tolerance. It was confirmed by the results of additional tests that includes among others echocardiography and MRI.

\section{Arrhythmia}

Cocaine increases the risk of arrhythmia, due to excessive adrenergic stimulation and it also affects the blockage of sodium and potassium channels. In small doses the effect of stimulation of the adrenergic system dominates, in large doses, it blocks ion channels. [16] Usage of cocaine induces ventricular and supraventricular arrhythmias. It can cause sinus tachycardia or atrial fibrillation when arrhythmia is the result of excessive adrenergic stimulation. The blockade of potassium channels causes QT interval prolongation, which can lead to ventricular tachycardia, including torsade de pointes. Cocaine-induced myocardial ischemia can cause ventricular tachycardia or ventricular fibrillation. [17]

The first-line treatment is B-blockers in combination with alpha-blockers. Sodium bicarbonate and lidocaine are also used. Have Cablockers been shown to reduce arrhythmia? It is important to correct electrolyte disturbances. Arrhythmias resistant to pharmacological treatment can be corrected by cardioversion or defibrillation. It has been proven that ablation is feasible, safe and effective in patients with drug-resistant cocaine-induced tachycardia. [18] The most common cause of sudden death in people addicted to cocaine is ventricular fibrillation. [19] The main therapeutic goal of a patient experiencing cocaine-related arrhythmia is the abstinence of using cocaine.

During the hospitalization of the patient in the ECG monitoring, no arrhythmias were recorded.

\section{Endocarditis}

Cocaine is one of the most commonly used drugs for intravenous use. This route of administration is associated with a high risk of endocarditis.

Cocaine also has a damaging effect on the vascular endothelium. Endocarditis in drug users is mostly on the tricuspid valve. [20] Treatment consist of multi-week antibiotic therapy but the most important goal is to stop using cocaine.

The results of laboratory tests and the result of MRI allowed to rule out endocarditis at the patient. 


\section{Stroke}

Strokes occur most often in older patients. However recently there was an increase in a number of incidences among younger people, which is related to the use of illegal drugs. Cocaine increases the risk of ischemic and hemorrhagic stroke. [21] The most common causes of ischemic strokes in patients using cocaine are atherosclerotic stenosis of the large artery and occlusion of the small cerebral vessels.

Vasoconstriction and prothrombotic properties increase the risk of ischemic stroke. The use of cocaine accelerates the process of atherosclerosis. [22] Longterm use of cocaine increases the risk of stroke, including endothelial changes, atherosclerosis and vasculitis. Most ischemic cocaine-related strokes occur in people with a distant history of cocaine use.

Hemorrhagic strokes are associated with a sudden rise in blood pressure after cocaine ingestion. They are more common in active cocaine users. The most common cause is rupture of the aneurysm. [23] It has been proven that brain aneurysms are likely to happen to people who use cocaine. The use of cocaine is associated with a greater probability of hemorrhagic stroke than ischemic stroke. [24]

The patient did not show symptoms of neurological deficit. Diagnosis for stroke has not been extended.

\section{Conclusion}

As demonstrated, cocaine has many negative effects on the cardiovascular system. One of the main goals of treatment is total abstinence. An important aspect is to make patients aware of the consequences of further cocaine use. Cocaine use can cause both short-term and long-term effects.

In young patients presenting cardiovascular disease symptoms, but not having any other loads, the drug use should be considered in the diagnosis, because it is most often occurs in this age group.

In this case report, the patient was diagnosed with toxic cocaine cardiomyopathy. The direct cause of the disease was long-term and regular use of this drug.

The patient was qualified for ICD implantation as the primary prevention of sudden cardiac death.

\section{References}

1. Fischman MW, Schuster CR, Fischman MW, et al. Cardiovascula and subjective effects of intravenous cocaine administration in humans. Arch Gen Psychiatry. 1976; 33(8): 983-989, doi: 10.1001/archpsyc.1976.01770080101010, indexed in Pubmed: 949232.

2. Egashira K, Morgan KG, Morgan JP. Effects of cocaine on excitation-contraction coupling of aortic smooth muscle from the ferret. $J$ Clin Invest. 1991; 87(4): 1322-1328, doi: 10.1172/JCl115135, indexed in Pubmed: 2010545
3. Kolodgie FD, Virmani R, Cornhill JF, et al. Increase in atherosclerosis and adventitial mast cells in cocaine abusers: an alternative mechanism of cocaine-associated coronary vasospasm and thrombosis. J Am Coll Cardiol. 1991; 17(7): 1553-1560, doi: 10.1016/07351097(91)90646-q, indexed in Pubmed: 2033185.

4. Minor RL, Scott BD, Brown DD, et al. Cocaine-induced myocardial infarction in patients with normal coronary arteries. Ann Intern Med. 1991; 115(10): 797-806, doi: 10.7326/0003-4819-115-10-797, indexed in Pubmed: 1929028.

5. Hollander JE, Hoffman RS, Gennis P, et al. Prospective multicenter evaluation of cocaine-associated chest pain. Cocaine Associated Chest Pain (COCHPA) Study Group. Acad Emerg Med. 1994; 1(4): 330-339, indexed in Pubmed: 7614278.

6. Weber JE, Chudnofsky CR, Boczar M, et al. Cocaine-associated chest pain: how common is myocardial infarction? Acad Emerg Med. 2000; 7(8): 873-877, doi: 10.1111/j.1553-2712.2000.tb02064.x, indexed in Pubmed: 10958126

7. Bosch X, Loma-Osorio P, Guasch E, et al. Prevalence, clinical characteristics and risk of myocardial infarction in patients with cocaine-related chest pain. Rev Esp Cardiol. 2010; 63(9): 1028-1034, doi: 10.1016/s1885-5857(10)70206-1, indexed in Pubmed: 20804698

8. Anderson JL, Adams CD, Antman EM, et al. American College of Cardiology Foundation/American Heart Association Task Force on Practice Guidelines. 2012 ACCF/AHA focused update incorporated into the ACCF/AHA 2007 guidelines for the management of patients with unstable angina/non-ST-elevation myocardial infarction: a report of the American College of Cardiology Foundation/American Heart Association Task Force on Practice Guidelines. Circulation. 2013; 127(23): e663-e828, doi: 10.1161/CIR.0b013e31828478ac, indexed in Pubmed: 23630129

9. Rangel C, Shu RG, Lazar LD, et al. Beta-blockers for chest pain associated with recent cocaine use. Arch Intern Med. 2010; 170(10): 874-879, doi: 10.1001/archinternmed.2010.115, indexed in Pubmed: 20498415

10. McCord J, Jneid H, Hollander JE, et al. American Heart Association Acute Cardiac Care Committee of the Council on Clinical Cardiology. Management of cocaine-associated chest pain and myocardial infarction: a scientific statement from the American Heart Association Acute Cardiac Care Committee of the Council on Clinical Cardiology. Circulation. 2008; 117(14): 1897-1907, doi: 10.1161/CIRCULATIONAHA.107.188950, indexed in Pubmed: 18347214

11. Su J, Li J, Li W, et al. Cocaine induces apoptosis in primary cultured rat aortic vascular smooth muscle cells: possible relationship to aortic dissection, atherosclerosis, and hypertension. Int J Toxicol. 2004; 23(4): 233-237, doi: 10.1080/10915810490471361, indexed in Pubmed: 15371167.

12. Cerretani D, Fineschi $\mathrm{V}$, Bello $\mathrm{S}$, et al. Role of oxidative stress in cocaine-induced cardiotoxicity and cocaine-related death. Curr Med Chem. 2012; 19(33): 5619-5623, doi: 10.2174/09298671280398878 5 , indexed in Pubmed: 22856662.

13. Pitts WR, Vongpatanasin W, Cigarroa JE, et al. Effects of the intracoronary infusion of cocaine on left ventricular systolic and diastolic function in humans. Circulation. 1998; 97(13): 1270-1273, doi: 10.1161/01. cir.97.13.1270, indexed in Pubmed: 9570197.

14. Freeman K, Feldman JA. Cocaine, myocardial infarction, and beta-blockers: time to rethink the equation? Ann Emerg Med. 2008; 51(2): 130-134, doi: 10.1016/j.annemergmed.2007.08.020, indexed in Pubmed: 17933425

15. Brody S, Slovis C, Wrenn K. Cocaine-related medical problems: Consecutive series of 233 patients. The American Journal of Medicine. 1990; 88(4): 325-331, doi: 10.1016/0002-9343(90)90484-u.

16. Wood DM, Dargan PI. Putting cocaine use and cocaine-associated cardiac arrhythmias into epidemiological and clinical perspective. Br J Clin Pharmacol. 2010; 69(5): 443-447, doi: 10.1111/j.13652125.2010.03630.x indexed in Pubmed: 20573079.

17. Hoffman RS. Treatment of patients with cocaine-induced arrhythmias: bringing the bench to the bedside. Br J Clin Pharmacol. 2010; 69(5): 448-457, doi: 10.1111/j.1365-2125.2010.03632.x, indexed in Pubmed: 20573080

18. Lakkireddy D, Kanmanthareddy A, Biria M, et al. Radiofrequency ablation of drug refractory ventricular tachycardia related to cocaine use: a feasibility, safety, and efficacy study. J Cardiovasc Electrophysiol. 2014; 25(7): 739-746, doi: 10.1111/jce.12432, indexed in Pubmed: 24724798

19. Bauman J, Grawe J, Winecoff A, et al. Cocaine-Related Sudden Cardiac Death: A Hypothesis Correlating Basic Science and Clinical Observations. The Journal of Clinical Pharmacology. 2013; 34(9): 902-911, doi: 10.1002/j.1552-4604.1994.tb04003.x. 
20. Frontera JA, Gradon JD. Right-side endocarditis in injection drug users: review of proposed mechanisms of pathogenesis. Clin Infect Dis. 2000; 30(2): 374-379, doi: 10.1086/313664, indexed in Pubmed: 10671344

21. Westover AN, McBride S, Haley RW. Stroke in young adults who abuse amphetamines or cocaine: a population-based study of hospitalized patients. Arch Gen Psychiatry. 2007; 64(4): 495-502, doi: 10.1001/archpsyc.64.4.495, indexed in Pubmed: 17404126.

22. Kolodgie FD, Virmani R, Cornhill JF, et al. Increase in atherosclerosis and adventitial mast cells in cocaine abusers: an alternative mechanism of cocaine-associated coronary vasospasm and thrombosis. J Am Coll Cardiol. 1991; 17(7): 1553-1560, doi: 10.1016/07351097(91)90646-q, indexed in Pubmed: 2033185.

23. Toossi S, Hess CP, Hills NK, et al. Neurovascular complications of cocaine use at a tertiary stroke center. J Stroke Cerebrovasc Dis. 2010; 19(4): 273-278, doi: 10.1016/j.jstrokecerebrovasdis.2009.05.002, indexed in Pubmed: 20444626

24. Fonseca AC, Ferro JM. Drug abuse and stroke. Curr Neurol Neurosci Rep. 2013; 13(2): 325, doi: 10.1007/s11910-012-0325-0, indexed in Pubmed: 23299821 